\title{
Healthcare providers' digital competency: a cross-sectional survey in a low-income country setting
}

\author{
Kirubel Biruk Shiferaw ${ }^{1 *} \mathbb{D}$, Binyam Chakilu Tilahun ${ }^{2}$ and Berhanu Fikadie Endehabtu²
}

\begin{abstract}
Background: Healthcare providers across all clinical practice settings are progressively relying and adapting information communication technologies to perform their professional activities. In this era of technology, healthcare providers especially in lower income countries should have at least basic digital competency if a successful application of technology is to be achieved. The aim of this study was to assess digital competency of healthcare providers among seven public health centers in North-West Ethiopia.

Methods: A cross-sectional study design was applied to assess the basic digital competency of healthcare providers working in seven public health centers in North-west Amhara regional state, Ethiopia. Self-administered questionnaire adopted from the European commission's digital competency framework for assessing digital competency were used. A multivariable logistic regression was performed to identify factors associated with basic digital competency with $p$-value $<0.05$ as a rule out for statistical significance. The strength of association was explained in terms of coefficient estimate, adjusted odds ratio and a 95\% confidence interval (CI).

Result: From the total of 193 healthcare providers included in the study, 167 of them responded which is a response rate of $86.5 \%$. The majority of respondents 88 (52.7\%) were males and the mean age was 28.2 years with a standard deviation of 5.5 years. The result indicated that all items demonstrated an adequate level of internal consistency with Cronbach alpha $>0$.7. Healthcare providers in those public health centers reported that problem solving, safety and communication are the most common challenges encountered. The multivariable logistic regression model indicated that factors such as sex, educational status, profession type, monthly income and years of experience are statistically significant predictors.
\end{abstract}

Conclusion: Basic digital competency level of healthcare providers working in public health centers in this setting is relatively low. The results highlight the need to improve digital competency among healthcare providers focusing on the identified skill gaps.

Keywords: Digital competency, Digital literacy, Healthcare providers, eHealth, Low income country, Digital health

\footnotetext{
*Correspondence: birukkirubel@gmail.com

'Department of Health Informatics, Debre Markos University, Health Science College, Debre Markos, Ethiopia

Full list of author information is available at the end of the article
}

(C) The Author(s). 2020 Open Access This article is licensed under a Creative Commons Attribution 4.0 International License, which permits use, sharing, adaptation, distribution and reproduction in any medium or format, as long as you give appropriate credit to the original author(s) and the source, provide a link to the Creative Commons licence, and indicate if changes were made. The images or other third party material in this article are included in the article's Creative Commons licence, unless indicated otherwise in a credit line to the material. If material is not included in the article's Creative Commons licence and your intended use is not permitted by statutory regulation or exceeds the permitted use, you will need to obtain permission directly from the copyright holder. To view a copy of this licence, visit http://creativecommons.org/licenses/by/4.0/ The Creative Commons Public Domain Dedication waiver (http://creativecommons.org/publicdomain/zero/1.0/) applies to the data made available in this article, unless otherwise stated in a credit line to the data. 


\section{Background}

Worldwide, various public and privet sectors are fetching and effectively utilizing simple and advanced technological artifacts to improve their productivity and maintain their competitive advantage [1]. The healthcare sector is one of the potential application areas where advanced technologies could improve health service and health system as a whole [2-4]. The healthcare sector has been known for its slower adoption of new technologies [5, 6] and it is even slower in middle and low income countries [7-9]. However, health care professionals across all clinical practice settings are progressively relying and adapting information communication technologies to perform their professional activities [10-13]. Several studies have identified the need for a certain level of digital competency in order to make an efficient and effective use of technologies among different allied health professions [14-16]. Digital competency of healthcare providers could greatly help the adoption of Electronic Medical Record systems (EMRs) and online risk assessment and decision support tools, as well as the introduction of cutting-edge medical equipment which often have digital user interfaces.

The concept of digital literacy/competency is also known as digital information literacy. Digital information literacy is defined by the European Union Commission as "the set of knowledge, skills, attitudes, abilities, strategies, and awareness that are required when using ICT and digital media to perform tasks; solve problems; communicate; manage information; collaborate; create and share content; and build knowledge effectively, efficiently, appropriately, critically, creatively, autonomously, flexibly, ethically, reflectively for work, leisure, participation, learning, and socializing" [17, 18].

In this era of technology, healthcare professionals particularly in low-income countries should have at least a minimum level of digital competency if technology is to be applied successfully. Studies have identified the need to bridge the digital skill gap of healthcare providers in order to transfer technology to the point where health service quality is maintained. However, most of these studies do not specify in detail where the critical digital skill gap lays [19-21]. By itself, digital literacy is a congregating and evolving concept through time and advancement in technology. Thus, Martin (2006) argues the need to maintain up to date level of digital skill. Martin (2006) asserted that digital literacy is not just a threshold one could achieve through certification and diploma at a point time. Rather, it is a temporary and context based concept referring only to the current level of performance [22]. As a result, assessing the level of digital competency should be conducted in parallel with the evolving changes in the digital environment.

In Ethiopia, the government has implemented a strategy that focuses on digitalizing the health system and currently, there are many eHealth project initiatives underway and most of these initiatives are faced with the challenge of sustainability. This could be the result of different factors including a low level of digital competency among target users [23-25]. To bridge this gap, the commonly proposed solution is to provide computer training for healthcare providers before or during the implementation of computerbased systems. However, we argue that offering general computer training might not be sufficient to bridge the digital competency gap. Based on the new system's requirement, one has to assess the proficiency level of user's digital literacy first. Low productivity, inefficiency and missed opportunities are the key consequences and real-world implications of low digital competency. This could mean medical information is lost or recorded incorrectly, technologies could pass by unadopted, general healthcare standards could fall behind contemporary standards, confidential patient information could be accessed by unauthorized parties, etc. According to the European commission's classification, digital users could be categorized as basic, intermediate and advanced users. Based on the technology's enquiry of digital skill level, one should assess the required digital literacy level of potential users and identify the core gaps which needs more attention. In such a way, one might have a clear understanding of the target population. Several studies pined the need to assess digital competency level of potential digital device users in order to give the appropriate level of education and training [26-28].

The European Commission has developed a digital competency framework to elucidate the context and aspects of digital competency. The framework identified five core digital literacy components (Information/data literacy, content creation, communication, problem solving and safety) to describe and understand the digital competency level of individuals [17]. To ensure a successful digitization of the health system in Ethiopia and other African countries, understanding the level of healthcare providers' digital competency could be considered baseline information. The aim of this study was to assess the basic digital competency level of healthcare providers among seven public health centers in North-West Ethiopia.

\section{Methods}

\section{Study design and setting}

A cross-sectional study design was applied to assess basic digital competency level of healthcare providers working in seven public health centers in North-west Amhara regional state, Ethiopia. Health centers are the smallest healthcare service delivery units next to health posts, which were established to improve healthcare coverage. There were approximately 4212 health centers and 18,151 health posts in Ethiopia when this study was conducted. The health centers were selected based on the priority list of health centers in which the Federal Minister of Health $(\mathrm{FMoH})$ and agencies planned to introduce electronic 
interventions such as EMR (Electronic Medical Record) systems or mHealth (Mobile Health) interventions. The Ethiopian FMoH have a strategic plan to substantially advance five major types of health information systems; Tele-education and Telemedicine, EMR/EHR (Electronic Medical Record/ Electronic Health Record), mHealth, eCHIS (electronic Community Health Information System) and eLMIS (Electronic Logistics Management Information System). This study is focused on the context of Electronic Medical Record systems (EMRs) in health facilities.

\section{Sample size and participants}

The health facilities have approximately 193 healthcare providers in total and all healthcare providers who are directly engaged in both clinical and non-clinical health service delivery were considered for the study. Since the total number of potential participants is relatively small, all healthcare providers were approached for data collection. Healthcare providers with annual and sick leave were excluded.

\section{Outcome and outcome measure}

The outcome variable is digital competency/literacy and it was measured by twenty-two items divided in to five major components [17]. All items were measured in 5-point Likert scale ranging from strongly agree (5) to strongly disagree (1). The first component was information processing. Information processing is an important element in understanding the competency level of participants focused majorly on individual's ability to search, find, appraise, sort, store and retrieve information using digital devices. The second component is Content creation. Content creation describes an individual's ability to create/delete /manipulate contents such as text and images in different application software such as Microsoft Word and Excel in digital devices. It also includes adjusting settings based on one's interest of use. On the other hand, communication focuses on an individual's capability to communicate, share and interact with others using digital devices and network. It includes internet or local area connections. Problem solving focuses on assessing the skill of individual's potential in solving routine hardware and software problems encountered while using digital devices. Problem solving also evaluates where a person stops working when difficulties appear or they look for digital solutions. The last component is Safety, which assesses what people do to protect their devices from cyber/physical attack and the precautions they take on their own health. For this study, we used a paper-based self-administered questionnaire adopted from European commission's digital competency framework for assessing digital competency [17]. Due to the nonnormal distribution of outcome variable, scores less than the median value were labelled 'low digital competency', while scores greater-than-or-equal-to the median value were labelled 'high digital competency'. Internal consistency of items was assessed using Cronbach alpha. The tool was adopted the European commission's digital competency framework and pretested on 30 [29] healthcare providers in Debremarkos health center for its content validity and readability (Kirubel Tool). Data collectors were recruited and trained to maintain the data quality and continuous supervision was performed by the investigators during the study period.

\section{Quality control \& analysis methods}

Data collectors were given half a day training on correct participant approach and data handling. Data collectors were supervised during the data collection period. Following this, data were checked for completeness and accuracy, then entered into the Statistical Package for Social Science (SPSS version 23) for further analysis. Descriptive statistics were calculated to summarize healthcare providers' socio-demographic characteristics. Before running the multivariable logistic regression, assumptions for multicollinearity, outliers and independent error terms were tested. Multicollinearity was verified by running a pseudo linear regression repeating the independent variables as an outcome variable. The results confirmed the absence of multicollinearity with a variance inflation factor (VIF) value less than three and tolerance greater than 0.7 [30]. No significant outlier effect was observed in the box plot. Goodness of model fit was tested using omnibus test for global fitness; the Hosmer and Lemeshow test was applied to examine fitness of the data to the model. Accordingly, the omnibus test result was significant with $p$-value $<0.05$ and the Hosmer and Lemeshow test shows a good model fit with $p$-value $=0.712$ indicating good model fitness [31] . A multivariable logistic regression was applied to identify factors associated with basic digital competency with $p$ value $<0.05$. The strength of association was explained in terms of coefficient estimate, adjusted odds ratio and a 95\% confidence interval $(\mathrm{CI})$.

\section{Result}

From the total of 193 healthcare providers included in the study, $86.5 \%$ (167) of them responded to the invitation to participate. The majority of respondents $88(52.7 \%)$ were males and the mean age was 28.2 years with a standard deviation of 5.5 years. Diploma holders were relatively larger in number with 93 (55.7\%) and most of the study participants were nurses with 83 (90.7\%). The average work experience of participants were 4.6 years with a standard deviation of 3.9 years. Table 1 summarizes the sociodemographic characteristics of study participants.

The result indicated that all items demonstrated an adequate level of internal consistency with Cronbach alpha $(\alpha>0.7)$ [32]. One can score minimum of 22 and maximum of 110 points from the digital competency 
Table 1 Socio- demographic characteristics of participants

\begin{tabular}{lll}
\hline Socio-demographic characteristics & Number & Percent \\
\hline Sex & 88 & 52.7 \\
Male & 79 & 47.3 \\
Female & & \\
Educational Status & 93 & 55.7 \\
Diploma & 71 & 42.5 \\
Degree & 3 & 1.8 \\
Master & & \\
Profession type & 83 & 49.7 \\
Nurse & 13 & 7.8 \\
Health Officer & 13 & 7.8 \\
Medical laboratory & 34 & 20.4 \\
Midwifery & 24 & 14.4 \\
Pharmacy & & \\
Monthly Income & & \\
1500-3500 & 45.7 \\
$3501-5500$ & 107 & 64.1 \\
>5500 & 15 & 9.0 \\
\hline
\end{tabular}

The currency of Monthly income is in Ethiopian birr (ETB)

items. Almost half of the participants (49.7\%) reported that they have high digital competency. From the components of digital competency, problem solving, safety and communication were the lowest rated with 73.1, 63.5 and $58.7 \%$ reporting a low level of competency respectively (See Table 2).

Figure 1 shows that healthcare providers reported that problem solving (solving routine hardware and software problems encountered while using digital devices/systems), safety (ability to take safety measures in regard with the user and the devices/systems) and communication (ability to communicate, share and interact with others using digital devices/systems) are the most common challenges encountered. In contrast, information processing (ability to search, find, appraise, sort, store and retrieve information using digital devices) and content creation skills (ability to create/delete /manipulate contents such as text and images) are relatively easier tasks. (see Fig. 1).
The multivariable logistic regression model indicated that factors such as sex, educational status, profession type, monthly income and year of experience are statistically significant predictors of healthcare providers' digital competency in this setting. The results also indicated that medical laboratory professionals and pharmacists demonstrated relatively lower digital competency level compared to nurses. Higher monthly income and increased years of experience are also associated with lower digital competency. (see Table 3).

\section{Discussion}

The findings from this study suggest that healthcare providers working in health centers lack problem solving, safety and communication competencies in using digital devices. Sex, educational status, profession type, monthly income and years of experience were statistically significant factors that influenced participants' overall level of digital competency.

To the authors' knowledge, this is the first study to assess basic digital competency level of healthcare providers that uses the European commission's digital competency framework.

The increasing prominence of information communication technologies (ICTs) in healthcare setting has prompted numerous studies to identify bottlenecks and discover means to successfully implement ICT in the healthcare settings [33, 34]. Studies outlined the need to build staff capacity in different ways including the provision of continuous and focused training for healthcare workers [35, 36]. Participants in this study demonstrated relatively low basic digital competency with majority of them reporting a lack of basic technical skills to solve routine hardware and software problems. This finding is similar to previous studies conducted in different settings (Scotland, Maryland) [15, $21,37]$ and in contrast with other studies reported higher digital competency of participants [38]. The difference could be due to difference in study setting where the staff composition and digital facilities in health centers are limited compared to tertiary and secondary hospitals. The finding implies that training focused on improving routine problem solving skills, communication, and safety measures could significantly improve the overall digital competency of healthcare workers. Unlike studies that confirm the

Table 2 Components of digital competency

\begin{tabular}{|c|c|c|c|c|c|c|}
\hline \multirow[t]{2}{*}{ Components } & \multicolumn{2}{|l|}{ Low } & \multicolumn{2}{|l|}{ High } & \multirow[t]{2}{*}{ Mean } & \multirow{2}{*}{$\begin{array}{l}\text { Standard } \\
\text { deviation }\end{array}$} \\
\hline & Frequency & $\%$ & Frequency & $\%$ & & \\
\hline Information processing & 83 & 50.3 & 84 & 49.7 & 10.0 & 3.3 \\
\hline Content creating & 87 & 52.1 & 80 & 47.9 & 16.7 & 5.2 \\
\hline Communication & 98 & 58.7 & 69 & 41.3 & 12.8 & 3.8 \\
\hline Safety & 106 & 63.5 & 61 & 36.5 & 16.1 & 4.8 \\
\hline Problem solving & 122 & 73.1 & 45 & 26.9 & 15.3 & 5.0 \\
\hline
\end{tabular}




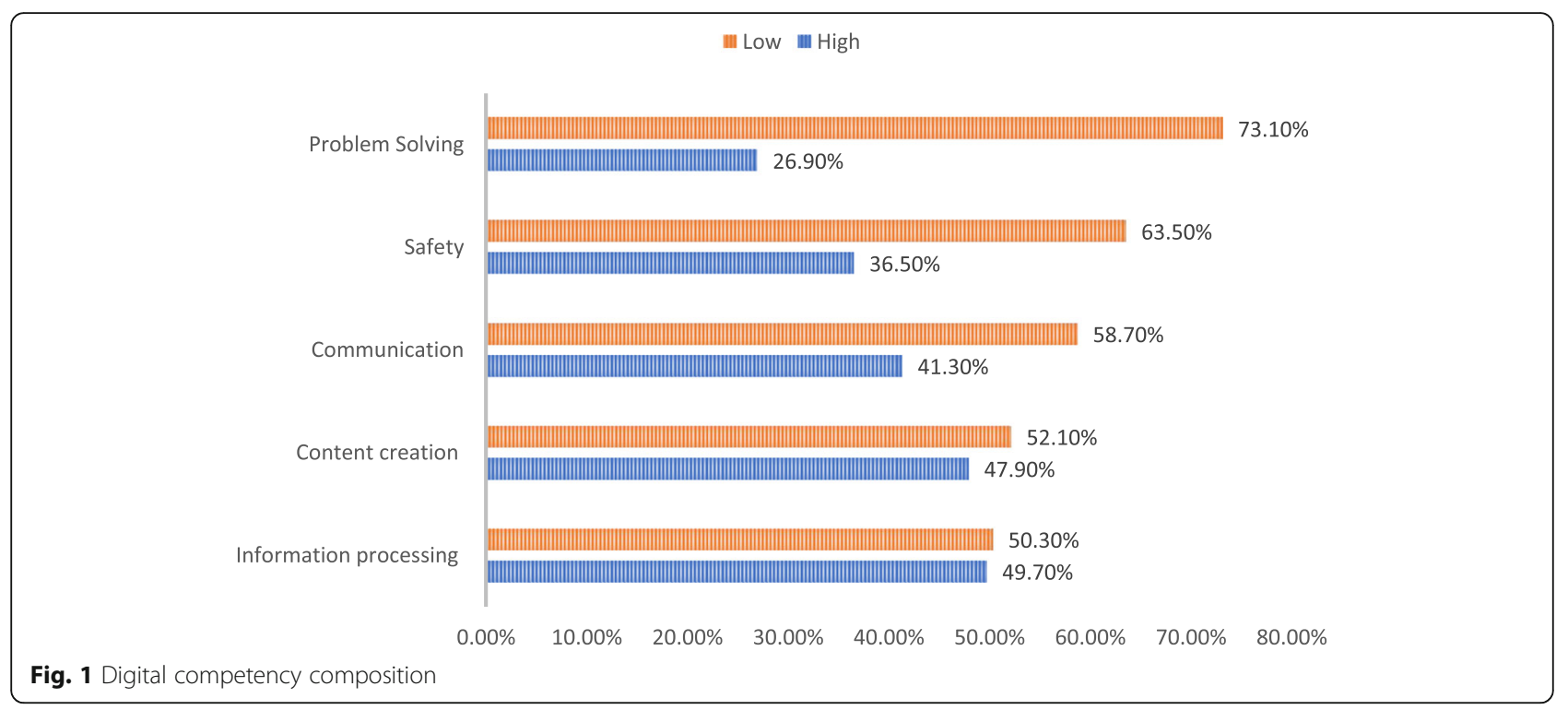

significance of age difference in predicting participants' digital competency level $[39,40]$, this study found that there is no significant association between participants' age and digital competency level. The possible explanation for this difference could be due to the fact that there is no significant generation gap in age distribution among participants in this study. On the other hand, sex was a significant

Table 3 Multivariable logistic regression results

\begin{tabular}{|c|c|c|c|c|c|}
\hline \multirow[t]{2}{*}{ Variables } & \multirow{2}{*}{$\begin{array}{l}\text { Coefficient } \\
\text { estimate }\end{array}$} & \multirow[t]{2}{*}{ AOR } & \multicolumn{2}{|c|}{$95 \% \mathrm{Cl}$} & \multirow{2}{*}{$\begin{array}{l}p \text { - } \\
\text { value }\end{array}$} \\
\hline & & & Lower & Upper & \\
\hline \multicolumn{6}{|l|}{ Sex } \\
\hline Male & 1.365 & 3.914 & 1.745 & 8.776 & $.001^{a}$ \\
\hline \multicolumn{6}{|l|}{ Female } \\
\hline Age & .105 & 1.111 & .924 & 1.336 & .262 \\
\hline \multicolumn{6}{|l|}{ Educational status } \\
\hline Diploma and below & -1.004 & .366 & .149 & .900 & $.029^{a}$ \\
\hline \multicolumn{6}{|l|}{ Degree and above } \\
\hline Profession Type & & & & & $.004^{\mathrm{a}}$ \\
\hline Health officer & -.694 & .499 & .198 & 1.263 & .142 \\
\hline Medical laboratory & -3.046 & .048 & .005 & .423 & $.006^{\mathrm{a}}$ \\
\hline Pharmacy & -2.437 & .087 & .013 & .600 & $.013^{\mathrm{a}}$ \\
\hline Midwifery & .531 & 1.700 & .476 & 6.076 & .414 \\
\hline \multicolumn{6}{|l|}{ Nurse } \\
\hline Monthly Income & & & & & $.005^{\mathrm{a}}$ \\
\hline \multicolumn{6}{|l|}{$1500-3500$} \\
\hline $3501-5500$ & -2.251 & .105 & .012 & .923 & $.042^{\mathrm{a}}$ \\
\hline$>5500$ & -2.931 & .053 & .008 & .372 & $.003^{\mathrm{a}}$ \\
\hline Year of Experience & -.372 & .689 & .518 & .918 & $.011^{\mathrm{a}}$ \\
\hline
\end{tabular}

Reference group: female, degree and above, nurse, 1500-3500, ${ }^{\text {indicates }}$ statistical significance, the currency of monthly income is in Ethiopian birr (ETB), AOR adjusted odds ratio variable in this study indicating male participants are more likely to possess higher digital competency with (AOR: 3.9 CI: 1.7-8.8). This finding is different from studies conducted elsewhere $[41,42]$ and in line with other studies [43, 44]. The possible reason for this disparity could be due to the fact that digital divide and gender inclusion is still a prominent challenge for middle- and lower-income countries such as Ethiopia. The finding also indicated that participants with an educational status of diploma and below are $63.4 \%$ less likely to possess high digital competency. This is consistent with other studies which report a positive relationship between higher education levels and high digital competency $[21,43]$. Profession type was also a predictive variable. Medical laboratory professionals and pharmacists demonstrated lower digital competency with 95.2 and $91.3 \%$ less likely to possess high digital competency level respectively. This finding is in line with other studies confirming that pharmacists lack digital competency [45, 46]. This implies that although some allied health professions are not directly engaged in the clinical care provision, their inability to work hand in hand with digital technology influences the overall success of technology adoption in the health sector. Therefore, providing tailored digital education for allied health professionals working in both clinical and non-clinical environments could improve the overall digital competency level of healthcare providers which in turn increases the likelihood of successful implementation of ICT in healthcare system. An increase in monthly income and years of experience are associated with lower digital competency. Participants with monthly income greater than 5500 ETB are $94.7 \%$ less likely to possess higher digital competency level with CI: $(0.008,0.372)$. A one unit increase in years of experience results in $31 \%$ less likelihood of possessing higher digital competency. In this study setting, an increase in income is associated with an 
increase in years of experience, where promotions are typically based on years of experience. This finding is similar to other studies indicating longer years of experience is associated with lower digital competency [21, 36, 46]. The possible reason could be that younger professionals are more receptive and adaptable to changes in the working environment compared to older ones. In almost all lower and lower middle income countries, the healthcare system is structured as an in-person or face-to-face model of care, and following the 2020 COVID-19 pandemics, the usual health care service has been altered significantly [47]. Although there is no clear evidence demonstrating a mismatch between patients and healthcare providers regarding their communication preferences, the global death toll resulting from COVID-19 has indicated the need to strengthen the digital capacity of health professionals and health services.

The present study is limited by a relatively small sample size. A larger group of representative samples from all health centers in Ethiopia would be more generalizable to the wider study population. It would also be more informative for decision makers if future research investigates basic, intermediate, and proficient levels of digital competency across a range of health professions.

\section{Conclusion}

This study found that sex, educational status, profession type, monthly income and years of experience all significantly impact healthcare providers' digital competency. Problem solving, communication and safety are the main reasons for lower scores in digital competency. The overall digital competency level of healthcare providers in our sample of north-west Ethiopia is relatively low. There is a clear need to improve digital competency in healthcare providers working in health centers in Ethiopia.

\section{Abbreviations \\ AOR: Adjusted Odds Ratio; Cl: Confidence Interval; SPSS: Statistical Package for Social Science; VIF: Variance Inflation Factor; FMoH: Federal Minister of Health; EMR: Electronic Health Record; mHealth: Mobile Health; eCHIS: Electronic Community Health Information System; eLMIS: Electronic Logistics Management Information System}

\section{Acknowledgements}

The authors would like to thank University of Gondar, Heads of health centers and participants for their cooperation.

\section{Authors' contributions}

$\mathrm{KB}$ made significant contributions in conception, design, data collection supervision, data analysis, interpretation and writeup of the manuscript. BC \& $\mathrm{BF}$ have contributed in extensively revising the manuscript, analysis and interpretation as well and all authors have approved the final version of this manuscript.

\section{Funding}

This study was financed by (Capacity Building and Mentorship Program) CBMP project eHealth lab Ethiopia. The funding office had no direct or indirect involvement in the study write-up and analysis; it was only involved in budgeting and budget evaluation.

\section{Availability of data and materials}

The datasets used and/or analyzed during the current study is available from the corresponding author on reasonable request.

\section{Ethics approval and consent to participate}

Ethical clearance was obtained from the University of Gondar Institute of Public Health Ethical Review Board. Additional permissions were secured from the respective health centers (Maksegnit, Loza, Gedebye, Ambagiorgis, Musebamb, Sanja and Maraki Health centers) to access participants and written informed consent from the study participants were maintained.

\section{Consent for publication}

Not applicable.

\section{Competing interests}

The authors declare that they have no competing interests.

\section{Author details}

'Department of Health Informatics, Debre Markos University, Health Science College, Debre Markos, Ethiopia. ${ }^{2}$ Department of Health Informatics, University of Gondar, Institute of Public Health, Gondar, Ethiopia.

Received: 3 August 2020 Accepted: 21 October 2020

Published online: 09 November 2020

\section{References}

1. Daniotti B, Pavan A, Lupica Spagnolo S, Caffi V, Pasini D, Mirarchi C. Evolution of the Building Sector Due to Digitalization. In: BIM-Based Collaborative Building Process Management. Springer Tracts in Civil Engineering. Cham: Springer; 2020.

2. Bulson J, Van Dyke M, Skibinski N. Rebooting healthcare information technology downtime management. J Bus Contin Emer Plan. 2017;11(1):63-72.

3. Piscotty RJ Jr, Kalisch B, Gracey-Thomas A. Impact of Healthcare Information Technology on Nursing Practice. J Nurs Scholarsh. 2015;47(4):287-93.

4. Yee KC, et al. How can information and communication technology improve healthcare inequalities and healthcare inequity? The concept of context driven care. Stud Health Technol Inform. 2018;247:591-5.

5. Pearce L. Digital literacy. Nurs Stand. 2017;31(48):18-20.

6. Farahat TM, Hegazy NN, Mowafy M. Information and communication technologies in primary healthcare facilities in Egypt. Prim Health Care Res Dev. 2018;19(1):88-95.

7. Liu G, et al. The development of health technology assessment in Asia: current status and future trends. Value Health Reg Issu. 2020;21:39-44.

8. Feroz A, Jabeen R, Saleem S. Using mobile phones to improve community health workers performance in low-and-middle-income countries. BMC Public Health. 2020:20(1):49.

9. Alam MZ, et al. Factors influencing the adoption of mHealth services in a developing country: a patient-centric study. Int J Inf Manag. 2020;50:128-43.

10. Barker R, Donnelly T. Transforming healthcare through technology. Healthc Pap. 2017;16(3):27-33.

11. Koster $Y$, van Houwelingen $C T$. Technology-based healthcare for nursing education within the Netherlands: past, present and future. Stud Health Technol Inform. 2017;232:101-10.

12. Heale R. Communication technology and healthcare. Evid Based Nurs. 2018; 21(2):36-7.

13. Ruiz Morilla MD, et al. Implementing technology in healthcare: insights from physicians. BMC Med Inform Decis Mak. 2017;17(1):92.

14. MacLure K, Stewart D. A qualitative case study of ehealth and digital literacy experiences of pharmacy staff. Res Soc Adm Pharm. 2018;14(6):555-63.

15. MacLure K, Stewart D. Self-reported digital literacy of the pharmacy workforce in north East Scotland. Pharmacy (Basel). 2015;3(4):182-96.

16. Gurdas Topkaya S, Kaya N. Nurses' computer literacy and attitudes towards the use of computers in health care. Int J Nurs Pract. 2015;21 (Suppl 2):141-9.

17. 2019]., A.J. European Digital Competence Framework for Citizens (DigComp). [online] Available at: https://ec.europa.eu/social/main. jsp?langld=en\&catld $=1315 \& 2019$.

18. Ferrari A. Digital competence in practice: An analysis of frameworks. Luxembourg: Publication office of the EU. Research Report by the Joint: 2012.

19. Mugomeri $E$, et al. Assessment of computer literacy of nurses in Lesotho. CIN. 2016;34(11):528-34. 
20. Bello IS, et al. Knowledge and utilization of information technology among health care professionals and students in Ile-Ife, Nigeria: a case study of a university teaching hospital. J Med Internet Res. 2004;6(4):e45.

21. Alwan K, Awoke T, Tilahun B. Knowledge and utilization of computers among health professionals in a developing country: a cross-sectional study. JMIR Hum Factors. 2015;2(1):e4

22. Martin A. A european framework for digital literacy. Nordic J Digit Lit. 2006; 1(2):151-61.

23. Fraser HS, Blaya J. Implementing medical information systems in developing countries, what works and what Doesn't. AMIA Annu Symp Proc. 2010;2010: 232-6.

24. Luna D, Otero C, Marcelo A. Health Informatics in Developing Countries: Systematic Review of Reviews. Contribution of the IMIA Working Group Health Informatics for Development. Yearb Med Inform. 2013;8:28-33.

25. Azubuike MC, Ehiri JE. Health information systems in developing countries: benefits, problems, and prospects. J R Soc Promot Heal. 1999;119(3):180-4.

26. Brunner $M$, et al. An eHealth capabilities framework for graduates and health professionals: mixed-methods study. J Med Internet Res. 2018;20(5): e10229.

27. Barakat A, et al. eHealth Technology Competencies for Health Professionals Working in Home Care to Support Older Adults to Age in Place: Outcomes of a Two-Day Collaborative Workshop. Med 2 0. 2013;2(2):e10.

28. Scott IA, Sullivan C, Staib A. Going digital: a checklist in preparing for hospital-wide electronic medical record implementation and digital transformation. Aust Health Rev. 2018;43:302-13.

29. Perneger, TV, et al. Sample size for pre-tests of questionnaires, vol. 24; 2014

30. O'brien RM. A caution regarding rules of thumb for variance inflation factors. Qual Quant. 2007:41(5):673-90.

31. Hosmer DW Jr, Lemeshow S, Sturdivant RX. Applied logistic regression, vol. 398: John Wiley \& Sons; 2013.

32. Westland JC. In: Westland JC, editor. Partial Least Squares Path Analysis, in Structural Equation Models: From Paths to Networks. Cham: Springer International Publishing; 2015. p. 23-46.

33. Laramee AS, et al. Learning from within to ensure a successful implementation of an electronic health record. CIN. 2011;29(8):468-77.

34. Fritz F, Tilahun B, Dugas M. Success criteria for electronic medical record implementations in low-resource settings: a systematic review. J Am Med Inform Assoc. 2015;22(2):479-88.

35. Biruk K, Abetu E. Knowledge and attitude of health professionals toward telemedicine in resource-limited settings: a cross-sectional study in north West Ethiopia. J Healthc Eng. 2018;2018:2389268.

36. Mohammed $\mathrm{E}$, et al. Knowledge and utilization of computer among health workers in Addis Ababa hospitals, Ethiopia: computer literacy in the health sector. BMC Res Notes. 2013;6(1):106.

37. Campbell CJ, McDowell DE. Computer literacy of nurses in a community hospital: where are we today? J Contin Educ Nurs. 2011;42(8):365-70.

38. Kuek A, Hakkennes S. Healthcare staff digital literacy levels and their attitudes towards information systems. Health inform J. 2020;26(1):592-612.

39. Ajami S, Bagheri-Tadi T. Barriers for adopting electronic health records (EHRs) by physicians. Acta Informatica Medica. 2013;21(2):129.

40. Huryk LA. Factors influencing nurses' attitudes towards healthcare information technology. J Nurs Manag. 2010;18(5):606-12.

41. Saleh $\mathrm{S}$, et al. Readiness of healthcare providers for eHealth: the case from primary healthcare centers in Lebanon. BMC Health Serv Res. 2016;16(1):644.

42. Sanqui RC, Declaro-Ruedas MYA. Knowledge and attitudes towards healthcare information technology of the rural health workers in SAMARICA, Occidental Mindoro, Philippines. Asian J Educ Soc Stud. 2020;7(1):26-32.

43. Jain $\mathrm{R}$, et al. Knowledge and utilization of computer among health-care professionals in Mumbai. J Indian Assoc Public Health Dent. 2020;18(1):97.

44. Kay R. Addressing gender differences in computer ability, attitudes and use: the laptop effect. J Educ Comput Res. 2006;34(2):187-211.

45. MacLure K, Stewart D. Digital literacy knowledge and needs of pharmacy staff: a systematic review. J Innov Health Inform. 2016;23(3):560-71.

46. Gour N, Srivastava D. Knowledge of computer among healthcare professionals of India: a key toward e-health. Telemed E Health. 2010;16(9): 957-62.

47. Keesara S, Jonas A, Schulman K. Covid-19 and health care's digital revolution. N Engl J Med. 2020;382(23):e82.

\section{Publisher's Note}

Springer Nature remains neutral with regard to jurisdictional claims in published maps and institutional affiliations.
Ready to submit your research? Choose BMC and benefit from:

- fast, convenient online submission

- thorough peer review by experienced researchers in your field

- rapid publication on acceptance

- support for research data, including large and complex data types

- gold Open Access which fosters wider collaboration and increased citations

- maximum visibility for your research: over $100 \mathrm{M}$ website views per year

At $\mathrm{BMC}$, research is always in progress.

Learn more biomedcentral.com/submissions 